\title{
TWO CASES OF PRIMARY TUBERCULOSIS AFTER IMMERSION IN SEWAGE-CONTAMINATED WATER
}

\author{
BY \\ F. J. W. MILLER and J. P. ANDERSON \\ From the Nuffield Department of Child Health, Royal Victoria Infirmary, Newcastle upon Tyne
}

(RECEIVED FOR PUBLICATION NOVEMBER 2, 1953)

Primary tuberculous infection is rarely thought to arise by routes other than by aerogenous spread into the lungs or ingestion of infected milk into the alimentary tract. Yet there is ample evidence that other routes of infection are possible, and we are beginning to recognize that extra-pulmonary infection is more common than formerly believed (Miller, 1953). Indeed, it seems that the child may be first infected with the tubercle bacillus from almost any bizarre accident.

Here we report the histories of two children in whom primary tuberculosis followed immersion in sewage-contaminated water. We cannot find any record that this method of infection has previously been reported in England, but we have found reports of five cases in the Scandinavian literature - cases so similar in clinical history to ours that we feel the possibility of this method of infection should be recognized and the sequence of events noted.

\section{The Literature}

The five cases are contained in two reports, one of three cases from Oslo (Gaustad, 1947), the other of two cases from Stockholm (Senécal, 1950). All concern children who developed primary tuberculosis within the recognized incubation time after immersion in sewage-contaminated water.

Four of the five children required resuscitation, the other was quickly rescued. All four suffered an immediate febrile illness with vomiting and diarrhoea. At this stage in three children the tuberculin tests were negative and chest radiographs normal. Between two and five weeks after recovery from the enteritis, a more insidious illness developed with malaise and fever unaffected by chemotherapy. Tuberculin tests were now positive and there was radiological evidence of primary pulmonary tuberculosis. The fifth child who had not been ill was examined 10 weeks after the accident and was found to be tuberculin positive; the chest radiograph showed an active primary complex in the right lung.
In no instance was there familial tuberculosis or known contact with the disease. Gaustad discovered a sewage effluent from a sanatorium 300 yards upstream from the site of the accident, and previous examination of the water had demonstrated the presence of virulent tubercle bacilli. In Senécal's cases also the children had fallen into sewagecontaminated river water. One negative bacteriological examination was made.

\section{Case Reports}

Case 1. In August, 1949, on the second day of a seaside holiday at a resort on the north-east coast of England, a 4-year-old boy ran along the concrete top of a sewer discharging into the sea. At the end he overbalanced, falling into the sea immediately in front of the mouth of the effluent. He went under, was submerged twice, and was being swept out to sea when he was rescued. After revival he was seen by a doctor but was not admitted to hospital, and was apparently well for the rest of the 10-day holiday, but on reaching home began to have sickness and diarrhoea. After a week or 10 days he went to school but was only there three days before he went to bed with a febrile illness, malaise and vague aches and pains. In this condition he was seen by one of us (F.J.W.M.) at the request of his family doctor on September 19, when he had been ill for a week and four weeks after his accident.

On examination he was febrile but not seriously ill, and the only abnormal physical sign was a spleen enlarged about 1 inch below the costal margin. The leucocyte and differential counts did not show anything abnormal; agglutination tests for enteric and abortus fevers were negative. But the tuberculin jelly test was positive and radiographs revealed appearances in the right lower lobe consistent with a primary tuberculous complex. The fever ran the usual course of primary 'fever of onset', settling in three weeks, and the boy was thereafter well until the last week in June, 1950. Then for a week he was vaguely unwell and on July 1, 1950, was seen by his family doctor. On July 4 he was admitted to hospital and seen again by us (F.J.W.M.). This illness was tuberculous meningitis, but after a full course of treatment he made a good recovery, and now three years later is in good health, attending school regularly. 
During his first illness his family, in comfortable social circumstances, was examined and no trace of tuberculosis was found: no other contact was known and none has appeared since.

Radiographs taken in October, 1953, have not shown any residual calcification in chest, abdomen, neck or skull, but this does not, of course, invalidate the fact that a shadow consistent with primary infection was visible on the first film in September, 1949.

Case 2. This child, aged $2 \frac{1}{2}$, was quite healthy and was staying with his parents at a holiday camp when he fell into an unguarded sewage tank. His father rescued him and after applying artificial respiration took him to the local cottage hospital where he was admitted. There he soon developed severe enteritis which was treated with chemotherapy and subsided. Radiographs of the chest showed right basal shadowing thought to be due to the inhalation of foreign material, but he did not have any symptoms of pulmonary illness, and after 10 days he went home apparently well. Thus he remained for three weeks but then became febrile, and developing a cough, was again admitted to hospital. His illness was at first considered to be caused by unresolved pneumonia, and further radiographs revealed shadows indicating inflammatory changes in the lower and mid-zones in the right lung. As in the previous child, all other laboratory tests, agglutination and stool cultures, failed to give evidence of other infection. Over the next two weeks there was some improvement with chemotherapy and antibiotics (sulphamezathine, penicillin and aureomycin) but thereafter he slowly deteriorated, losing weight and running a high temperature. His tuberculin reaction was found to be positive. Primary tuberculous bronchopneumonia was suspected, and treatment with streptomycin and P.A.S. was begun. Even so improvement was slow. After two months he was still ill, slightly cyanosed, with inspiratory stridor, a brassy cough and signs of consolidation at the base of the right lung. One choroidal tubercle was visible in the fundus of the right eye. Chest radiographs then showed patchy mottling in the left lower lobe with more extensive consolidation on the right side, and enlargement of both hilar shadows. The cerebrospinal fluid was normal. Treatment continued and there was little change for two more months, but thereafter he improved steadily, and one year after his accident was well. A radiograph at this time still showed bilateral basal shadows, and as time has elapsed, calcification has become visible on both sides though more on the right. He has remained well; throughout, his family have been well and there was no known contact with tuberculosis.

\section{Discussion}

The account of our two cases reveals an illness strikingly similar to that described by Gaustad (1947) and Senécal (1950). A healthy child inhales and swallows contaminated water during accidental immersion and then has gastro-intestinal symptoms which clear after a few days. Finally after two or three weeks of apparent good health a febrile illness without dramatic clinical signs ensues, and the evidences of disease indicate primary tuberculous infection.

We did not know the previous tuberculin state of either child, but in the north east of England only $2-3 \%$ of children are positive at 2 years and $6 \%$ by 4 years (Cammock and Miller, 1953). When young children are infected the index case can often be readily found. Neither were we able to investigate the bacteriology of the sewage. We do know, however, that virulent tubercle bacilli have been found in sewage from industrial towns in this part of England (Cummins, Davies and Acland, 1929). From America several authors, including Rhines (1935) and Pramer, Heukelekian and Ragotzkie (1950), have reported the survival of tubercle bacilli for many weeks despite chlorination of sewage. Gaustad and Senécal both warned of the danger from contaminated sewage, and Jensen and Jensen (1942) stressed the danger of bathing near sewage effluents because of the presence of significant numbers of tubercle bacilli.

We think that both our children underwent primary tuberculous infection. The circumstantial evidence is strong enough to suppose that the bacilli were inhaled during immersion, and thereafter a primary complex was formed in the lung. The infection in the second child from standing sewage water seems to have been much heavier than in the first, producing a heavy bilateral primary infection. That the shadow in the first case cleared completely without leaving calcification or other scarring is not exceptional, as this is often observed in children undergoing tuberculin conversion. That the first child developed tuberculous meningitis can be regarded as an unfortunate risk of primary infection, but as $85 \%$ of cases of tuberculous meningitis develop within a year of the primary infection the fact is an additional pointer to the nature of the first illness.

We therefore suggest that there is in England as well as in other countries a danger that sewage water may carry tubercle bacilli and that children coming into accidental contact with it may thereby become infected. Closer enquiry might reveal further cases, and we feel the syndrome should be known.

\section{Summary}

Two cases of primary tuberculous infection in children of 4 and $2 \frac{1}{2}$ years following immersion in sewage-contaminated water are reported. There appears to be a pattern of illness following this accident : immersion sometimes requiring resuscitatation, gastro-enteritis which resolves in a few days, 
and thereafter in the third or fourth week a febrile illness which finally reveals itself as primary tuberculosis.

We wish to record our thanks to Dr. J. A. O'Callaghan, the family doctor, for data relating to the first child, and to Dr. Cunningham, of Poole Sanatorium, for permission to use the notes of the second child.

\section{REFERENCES}

Cammock, R. M. and Miller, F. J. W. (1953). Lancet, 1, 158 Cummins, S. L., Davies, D. and Acland, C. M. (1929). Tubercle, 10 Cummins,

Gaustad, V. (1947). Acta tuberc. scand., 21, 281

Jensen, K. A. and Jensen, K. E. (1942). Ibid., 16, 217

Miller, F. J. W. (1953). Lancet, 1, 5.

Pramer, D., Heukelekian, H. and Ragotzkie, R. A. (1950). Publ. Hlth Rep. Wash., 65, 851 .

Rhines, C. (1935). Amer. Rev. Tuberc., 31, 493.

Senécal, P. (1950). Acta tuberc. scand., 24, 357. 